\title{
An Implementation of ITIL Guidelines for IT Support Process in a Service Organization
}

\author{
Malleswara Talla and Raul Valverde
}

\begin{abstract}
Service level management (SLM) is a challenge in a distributed systems environment because all processes should provide a consistent, reliable, and predictable service delivery. Early 1990s, most organizations established few service-level agreements (SLA) as the key performance indicators (KPI) but it was difficult to measure or monitor them in a distributed systems environment. The strength of Information Technology Infrastructure Library (ITIL) is the approach of integrating the SLM with the support processes at strategic, tactical, and operational levels. This paper focuses on implementing ITIL guidelines at an operational level for service desk, incidents, problems, and change management. The ITIL framework only provides guidelines, so a service organization needs to explore a methodology for evaluating existing service support processes and implementing ITIL guidelines for improvements. To this end, we investigate upon how to apply the ITIL framework for reengineering of IT service support process in an organization. The approach is actually implemented at a dentalcare service provider with ten dental clinics connected in Wide Area Network (WAN) and the data is collected into a central server in the main dental center. We first started with the process mapping, and then moved towards reengineering following ITIL guidelines, while collecting the results in key performance areas before and after the process reengineering. This paper used questionnaires, document reviews, archival records and observation techniques for collecting the data. The results demonstrated improvements in differing magnitudes. Some ststistical analysis such as mean and variance together with t-value distribution and null hypothesis were also developed to determine the quality of results. The paper is cautious about the limited scope of audience and the questionnaire which may compromise the results; however, the approach is useful in obtaining significant improvements when a company invests in integrating ITIL guidelines in to service support processes.
\end{abstract}

Index Terms-Information Technology Infrastructure Library, Information System, Key Performance Indicators, Service Level Agreement, Wide Area Network.

\section{INTRODUCTION}

The complexity of Information Technology (IT) systems makes it difficult to match customer requirements with the capabilities of service provider. Early 1990s, most service organizations established few service-level agreements (SLA) as key performance indicators (KPI) but it was difficult to measure/monitor them in a distributed systems environment [11]. To address these problems, many organizations adopted Information Technology Infrastructure Library (ITIL) [2] as a framework for improving the service support processes. In

Manuscript received October 9, 2012; revised November 23, 2012

The authors are with John Molson Business School, Concordia University, Montreal, Canada (e-mail: mrtalla@jmsb.concordia.ca; rvalverde@jmsb.concordia.ca ). the past, many IT organizations focused only on technical issues. Now, IT companies are focusing on providing a high quality service. IT became a part of daily business activities in every organization. The ITIL is not hardware or software, but it is a technique to manage the technology and communications in an optimal way. The ITIL is not just a set of rules that must be followed, but guidelines for IT service support process. The primary objective of the ITIL is to establish the best practices and improving the standard of IT service quality that customers should demand and providers should supply [2].

The ITIL can be used as a quality service guideline for objectives [2]: Better quality control, service level, efficiency, cost reduction, and effectiveness of information flow, SLAs, and control over business processes. ITIL plays an important role in helping a business organization to meet its objectives since it helps to manage the IT resources more efficiently. One should consider the environment (social, organizational, and physical), processes and their interdependencies among different dimensions of a company. A clinical information system (CIS) and end-user of a bio-medical application are depicted in Fig. 1 [5].

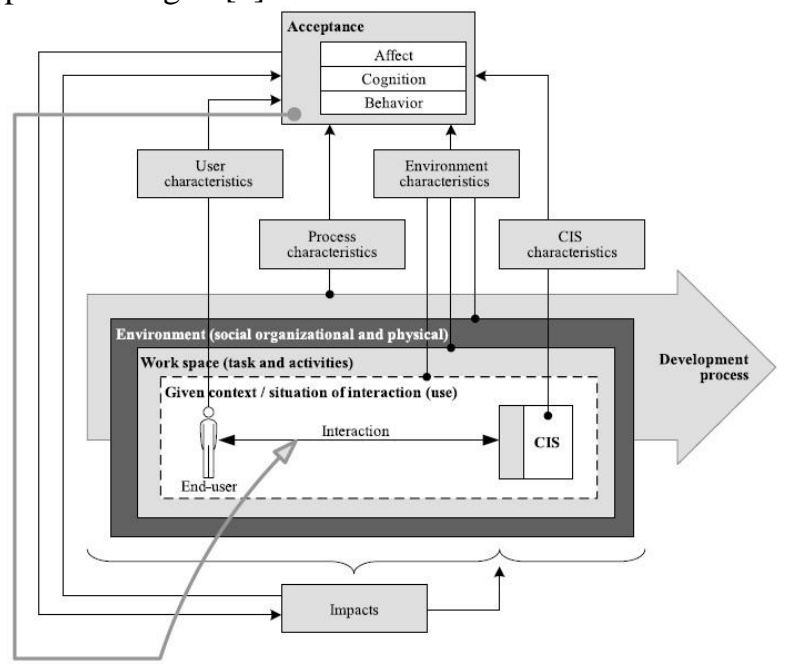

Fig. 1. The information system interaction model [5]

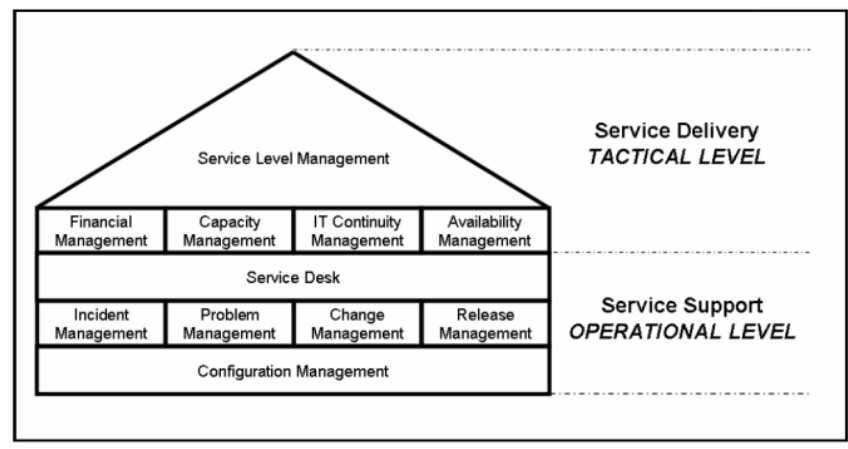

Fig. 2. ITIL core service management functions and processes [1] 
The ITIL framework for Service Delivery and Support process can be implemented at an operational level taking a good care of service support needs, and at a tactical level, improving the service delivery process, as presented in Fig. 2 The goal of this paper is to investigate how to use ITIL framework for reengineering IT service support process for improving the quality and reducing the cost of operations to strengthen the company's position in the market place.

\section{Methodology}

In this paper, a methodology consisting of process mapping and reengineering following ITIL guidelines is presented. A case study methodology is an exploratory research technique that investigates a contemporary phenomenon within real-life context [18]. The business process management systems (BPMS) actually track an organization's business processes and trigger improvements [6]. The IT tools provide a means for an enterprise data extraction via process mining; where important events logged can serve as pieces of information that could trigger process improvements [16]. A business process performs a set of activities and any improvements at activity level can accomplish a dynamic management of an enterprise process performance (Tan, 2008). A service model supports service planning, provisioning, operation and service management at customer-provider-interface [3]. The business process simulators can be used for decision support as well [17]. Likewise, every piece of information is useful for a successful reengineering of processes. The current research focuses on exploiting ITIL framework for improving the IT services that eventually improve the business processes. The IT Service Support companies are focusing on ensuring that their customers are better served of their IT needs [7]. The ITIL guidelines are widely used for improving IT service support processes [9]. The ITIL framework was successfully used in [8] for improving the incident management process. The efficient implementation of ITIL framework depends on building or procuring IT tools that can support them. The ITIL process-oriented tools such as workflow management systems are presented in [4]. The ITIL implementation can be cumbersome and time consuming if one doesn't follow a roadmap for improvement based on priorities, dependencies, and guidelines [13]. The experience of IT staff and the amount of time devoted for understanding IT needs, and creating an appropriate service management office (SMO) could help improve the success rate of IT services [10]. A case study of IT services in finance industry using ITIL guidelines is presented in [15].

An IT services company in Liverpool, UK, was selected for this ITIL implementation for one of their customers, specilizing dental care. The research starts with a description of the case study, its organizational structure, main business services and client base. The data collection is an important part in a case research. In this regard, [18] identified seven sources of empirical evidence in case studies, as follows:

- Documents: Written material (published and unpublished) documents, company reports, memos, administrative and departmental reports, e-mail messages, newspaper articles, or any document that presents some evidence/information.
- Archival records: Archival documents can be service records, organizational records, and lists of names, survey data, and other such records.

- Interviews: An interview can be used for identifying variables and their relationships; mainly for finding data.

- Questionnaires: structured questions written and supplied to a number of respondents over a large geographical area.

- Direct observation: via field visits. Rliability is enhanced when more than one observer is involved in the task.

- Participant-observation: in the events being studied.

- Physical artefacts: Physical artefacts can be instruments, tools, or some physical evidence that may be collected as part of a field visit, mainly for obtaining data.

We used questionnaires, documents review, archival records and observation techniques for collecting data. The use of observation as a method of data collection is presented in a [18]. In this study, the researcher visited the site of IS to observe its functionality, collected several documents that identify the business processes and describe their current operations. This will help researcher to learn details of IS included in the study. Archival records are an integral part of the data that needs to be collected. The main records that will be used are the problem logs that are kept for future enhancements. These records will help the researcher to identify areas of the IT services that will require modification for quality improvement. Based on data collected, researcher will perform a full analysis and benchmark ITIL framework in to IT service operations. Further, a study on the effectiveness of ITIL framework will be conducted to measure the improvements in the IT services after ITIL framework implementation. To do this, a small portion of the ITIL framework will be implemented and one group does the pretest-postest experiments as suggested in [19]. The pretest-post test experiment is a quasi-experiment in which the subjects in the experimental group are measured before and after the experiment is administered.The participants in experiments are selected via convenience sampling by invitation. This sampling technique refers to obtaining sample units or people who are available [19]. This method is justified since the participation in the study will be voluntary and it is difficult to anticipate the number of participants.

Further on, a questionnaire was used as a data-gathering device administered before and after implementation of ITIL framework. The questionnaire was concise and effective in addressing the required data based on the time and financial constraints. Questionnaires have a number of inherent advantages: sample population can be dispersed over a wide geographical area and respondents at their own convenience [12]. Furthermore, the participants are assured complete anonymity, self-administered questionnaires overcome the problems of interviewer bias while reducing the respondent's likely reluctance to convey an incorrect or controversial information. The questionnaires are reliable as they are easily repeated [14]. The espondents simply nominate a particular box to answer questions, no value judgements are required.

A simple-dichotonomy IT services evaluation questionnaire was developed and administered to the participants: the pre-ITIL test (pre-test) and post-ITIL test (post-test). Such questions requires the respodent to choose two alternatives (Yes and No) [19]. Both tests contain the 
same questions related to IT services that need to be evaluated. To analyze the data collected from questions, and ascertain general trends, descriptive statistics was used. The hypothesis that the ITIL framework helps to improve processes of the IT services which will be tested using t-Test for comparing the mean values of the pre-ITIL test and post ITIL test [19] in order to find the evidence of a possible effect of the ITIL framework in improving the quality of services.

One limitation of this study is its lack of generalisability since it involved only one set of data. However, the case study can be repeated to establish a certain generalisability. Another limitation can be the sample size that used a convenience sampling which may compromise the accuracy of results.

\section{PROCESS ANALYSIS}

The research involved ten dental clinics in different locations of Liverpool, that are connected via a high-speed WAN. The data is centralized into the IBM RS6000 server located in the main dental center. The user offices are equipped with workstations connected to the same WAN.

The scope of the IT services in this case study is as follows:

TABLE I: THE SCOPE OF THE IT SERVICES

\begin{tabular}{|c|c|}
\hline Services & Description \\
\hline Application Support & $\begin{array}{l}\text { For all matters related to application including } \\
\text { answering phone, fax, e-mail, written request } \\
\text { and so on. }\end{array}$ \\
\hline System Maintenance & $\begin{array}{l}\text { Bug fixing, System modification and data } \\
\text { conversion, Problem diagnosis, } \\
\text { and Documentation update }\end{array}$ \\
\hline $\begin{array}{l}\text { System Monitoring \& } \\
\text { Optimization }\end{array}$ & $\begin{array}{l}\text { Periodic performance monitoring and tuning } \\
\text { on the application system }\end{array}$ \\
\hline $\begin{array}{l}\text { Production Support } \\
\text { Ad-hoc Requests }\end{array}$ & $\begin{array}{l}\text { Liaise with all parties to collect and analyze } \\
\text { user requirements, data extraction, and } \\
\text { answering enquiries. }\end{array}$ \\
\hline $\begin{array}{l}\text { Environment and } \\
\text { Operation Support }\end{array}$ & $\begin{array}{l}\text { Perform backup and recovery, system } \\
\text { software upgrade and patches }\end{array}$ \\
\hline Procurement Support & $\begin{array}{l}\text { Provide support and advice regarding capacity } \\
\text { planning, technology substitutes and cost } \\
\text { estimations, h/w and s/w installation and } \\
\text { relocation }\end{array}$ \\
\hline $\begin{array}{l}\text { Planning, Drill Test and } \\
\text { Disaster Recovery } \\
\text { Business Resumption }\end{array}$ & $\begin{array}{l}\text { Conduct annual disaster recovery and } \\
\text { business resumption drill } \\
\text { Assist in resumption of business and } \\
\text { application in case of disaster }\end{array}$ \\
\hline $\begin{array}{l}\text { Project Management } \\
\text { and Reports }\end{array}$ & $\begin{array}{l}\text { Report system performance to management, } \\
\text { advice, approval and endorsement. } \\
\text { Coordinate and attend project meetings, } \\
\text { prepare agenda, minute and other related } \\
\text { documents }\end{array}$ \\
\hline
\end{tabular}

After analyzing current documents of IT service and the problem logs, the researcher was able to map current process and recommend changes to it, based on ITIL guidelines.

\section{A. Service Desk}

\section{1) Current Practice}

A support hotline was established that uses a Single Point of Contact (SPOC) for all incidents, as shown in Fig. 3.

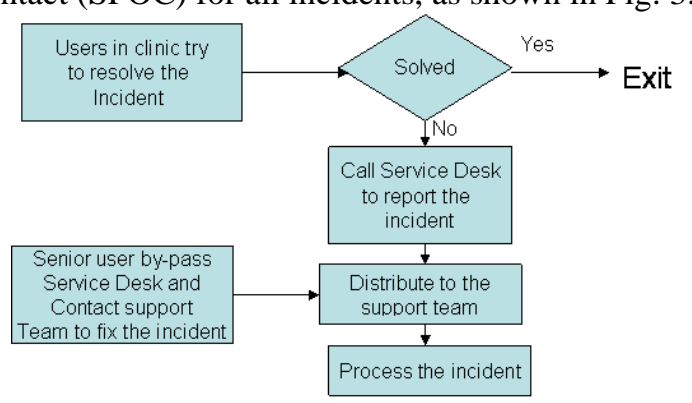

Fig. 3. Current practice of service desk

\section{2) Problems}

- In Fig. 3, the general users follow regular path whereas the senior users by-pass it.

- Not all users were aware of the scope of hotline support. Some out-of-scope incidents are not served by the support hotline. IT infrastructure and services should enable its users to customize their expectations. There should be a right balance among people, processes and technology.

\section{3) ITIL guidelines for Service Desk}

The ITIL guidelines (GL) for service desk are in Fig. 4.

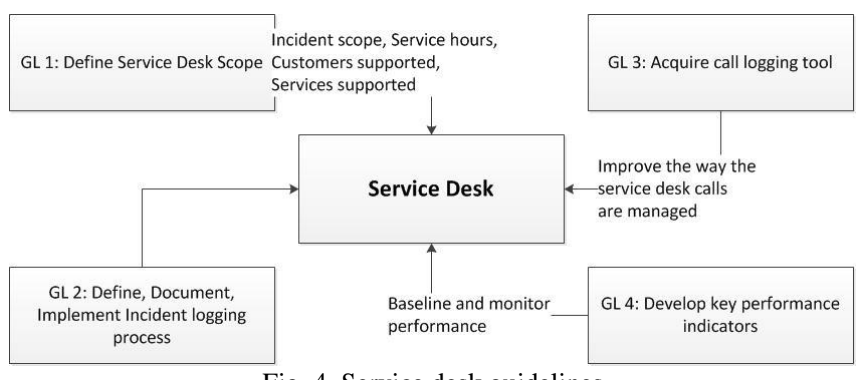

Fig. 4. Service desk guidelines

According to GL 1 in Fig. 4, SMISS system should define:

- Service hours

- Contact after service hours (mobile phone, email, etc.)

- Scope of services:

1) Problem incidents (h/w, s/w, application),

2) Change request, Ad-hoc query, and

3) Coordinate with the supplier (of $h / w$ and $s / w$ ) for procurement and maintenance issues

- Nature of incidents"

1) Application Help Desk type - dedicated support staff in normal office hours, plus mobile phone after hours.

2) "Fire" Fighting - solve emergency problem.

3) Problem management - solves a problem and coordinates with other suppliers to solve product issue

4) System Administration - provide server, LAN and database administration.

5) Ad-hoc request - Data Analysis \& Extraction.

6) Minor enhancement - impact analysis and enhancements with effort not more than 10 man days.

According to GL 2 in Fig. 4, the recommendations to the call logging procedure are:

- Contact details of business users, IT representative, clinic contact, $\mathrm{h} / \mathrm{w}$ and $\mathrm{s} / \mathrm{w}$ supplier and network should be in the Service Desk contacts list. For strategic direction issue, the members of maintenance board are the key users. The service desk should an efficient messaging system for broadcasting and point-to-point communications. 
- Incident reported through any channel should be logged. The service desk distributes incident to concerned entities.

- For incidents classified medium and severe, the service desk supervisor should ensure user satisfaction.

According to GL 3 in Fig. 4, Microsoft Excel is used to keep the call logs. Excel macro can be used to facilitate the $\log$ entry and to generate the statistics.

According to GL 4 in Fig. 4, the key performance indicators (KPI) to measure Service Desk are:

- Time to $\log$ the incident to the incident log database for calls via email, phone, or voice mail,

- Time to acknowledge the user,

- Time to categorize and prioritize the incident,

- Time to start the resolving action,

- Time to complete the action, and

- Percentage of number of satisfaction over the number of medium and high priority incidents.

\section{B. Incident Management}

\section{1) Current Practice}

Incident handling procedure was established to handle incidents as shown in Fig. 5.

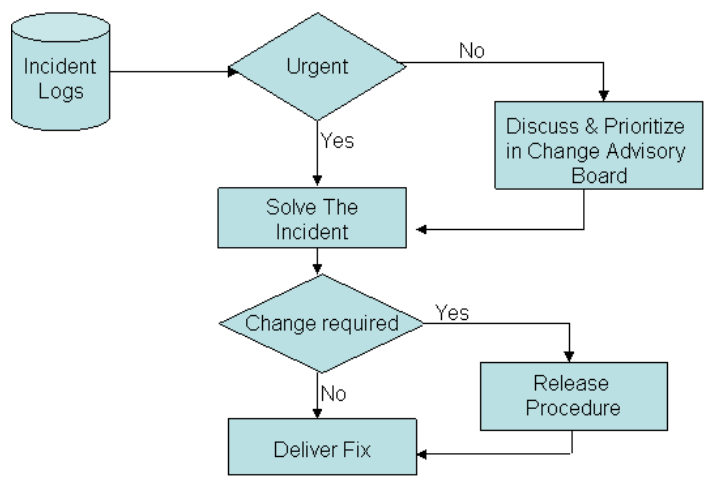

Fig. 5. Current Practice of Incident Management

\section{2) Problems}

- The log information was not enough for measuring the performance against the server level requirement. There was no escalation procedure defined and support team performance was not measured by any KPI.

- Each service desk staff actually maintained a separate log. The incidents were discussed and prioritized by the Change Advisory Board, but other users were not able to learn the status of the incident being reported.

\section{3) Recommendations to benchmark case study with ITIL}

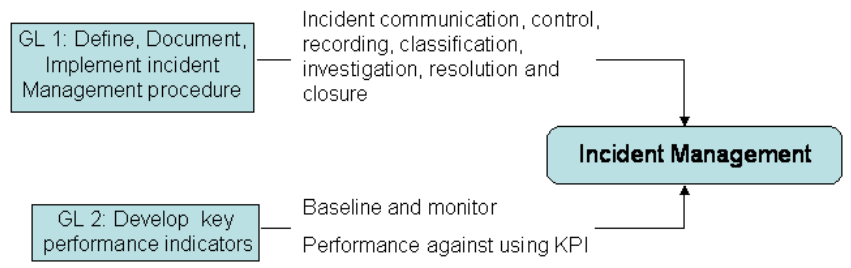

Fig. 6. Incident management guidelines

According to GL 1 in Fig. 6, SMISS system should define:

- Maintain centralized database for incident log

- Content of the incident log should include:

1) Unique identity number

2) Report date and time, Log date and time

3) Type of call (written, phone, voice message)
4) Nature of incident (h/w, s/w, network, etc.)

5) Acknowledgement date and time

6) Priority, Time to report to duty if after hours

7) Date, time, and priority of incident

8) Date and time of written reply

9) Date and time of completing analysis

10) Resolution, Date and time of resolution

11) Date and time of 3rd party involvement

12) Down time and workstations affected

13) Staff involved in the incident

14) Unique id of the configuration item

15) Effort estimation, Effort spent

- Type of the incident:

1) Application (custom developed $s / w$ )

2) Hardware, Software (OS, DBMS, etc.), Network

3) Ad-hoc query, Enhancement

4) Query about office automation tool

5) Query about application usage

6) Other

- Priority of the incident:

Urgent, High (complete in 3 days), Medium (complete in 2 weeks ), Low (complete in 2 months)

- Escalation procedure for reporting to support team manager if an incident cannot be solved within a period.

- Incidents $\log$ is posted to the Intranet site so that users are able to inquire the status of the incident in the log.

According to GL 2 in Fig. 6, the followings are the KPIs

for Incident Management:

- number of incidents in open state,

- number of incidents reported within the month,

- number of incidents solved within the month,

- number of incidents in closing state.

\section{Problem Management}

The current practice of Service Management Information Support System (SMISS) was mainly reactive, i.e. the support team solved the reported incidents. There was no procedure defined for proactive problem management (PM).

\section{1) Problems}

- The number of incidents was not reduced and the system could not be stabilized.

- Users stopped reporting the repeated incidents, but rebooted system to solve incidents.

- Support team prepared the data extraction manually for each clinic and repeated periodically. User data services effort was not reduced.

\section{2) Recommendations for problem management using} ITIL

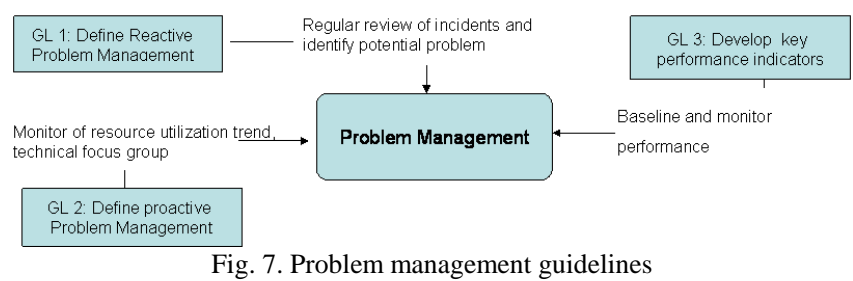

According to GL 1 in Fig. 7, SMISS system should define a reactive problem management, as follows:

- Conduct monthly review incidents should identify chronic problems by verifying the number of occurrences of the same or similar incidents. 
- Build a problem log database using a unique reference number for each problem, with the following attributes:

1) Problem reference number

2) Date/time of creation, Date/time of solution

3) Created by, Solved by

4) Major type (hardware, software or network)

5) Minor type (e.g. servers, workstation, or router)

6) Supplier (for example, Microsoft or CISCO)

7) Description of problem, Incident numbers

According to GL 2 in Fig. 7, SMISS system should define a proactive problem management. In general, the problems that are related to the network and CPU, could gradually downgrade the system performance. Users report incidents related to system performance when it becomes unacceptable. The resource utilization trend should be monitored to determine if the system (network or CPU) performance has fallen below an acceptable threshold.

- Build in-house technical focus groups. A focus group for SMISS could monitor OS, System Tools and database.

- A focus group will be able to solve any technical incidents efficiently in a proactive manner. The focus group should keep the support team informed of any possible problems that could occur in a timely manner.

According to GL 3 in Fig. 7, the KPIs are:

- number of incidents, number of problems, and

- average number of incidents related to a problem.

\section{Change Management}

\section{1) Current Practice}

The change management procedure which was established, addresses any change requests required as a result of incident logs, as presented in Fig. 8.

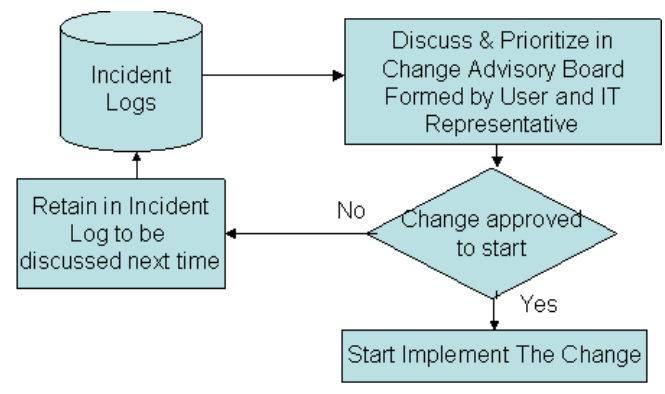

Fig. 8. Current practice of change management

\section{2) Problems}

- The maintenance board doesn't have representative from all functional groups which means, some decisions cannot be made effectively and efficiently.

- The procedure for issuing Request For Change (RFC) is specified; however duplicated requests were not filtered before passing them to the Change Advisory Board (CAB).

- Impact analysis was not conducted.

- There were no KPIs for measuring change management.

3) Recommendations for change management using ITIL

According to GL1 in Fig. 9, SMISS system should define scope of CAB:

- CAB should include representatives from IT department and staff from each clinic. The agenda and incidents will be distributed before $\mathrm{CAB}$ meeting and each functional group should arrange a representative to attend the meeting. The CAB will make decisions for deployment, further analysis, approval or cancellation of changes.

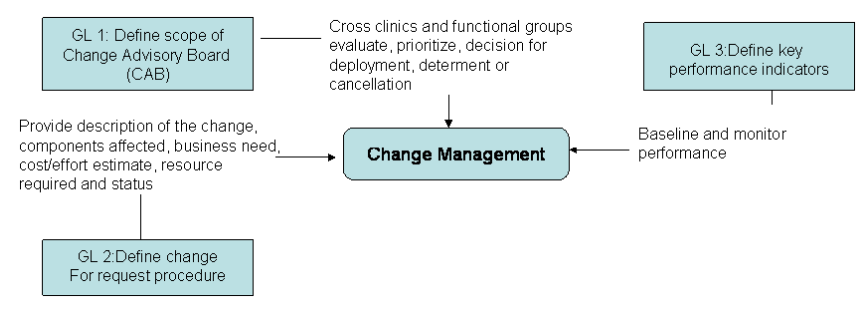

Fig. 9. Change management guidelines

According to GL2 in Fig. 9, the procedure of Request for Change (RFC) should be:

- Incidents that need change should be reviewed before the CAB meeting. Any duplication and unnecessary incidents should be filtered. The status of the filtered incidents will be distributed to the $\mathrm{CAB}$ members and the requestor.

- Board should analyze the technical and business impact. The analysis result should be assessed by the CAB.

- If the man-days required exceed the scheduled limit for the service that will affect the normal support service, then the $\mathrm{CAB}$ should determine whether to acquire extra budget for the request or to do it with support team resource but it has lower priority than the service request.

- Change for request should be issued after CAB approves the request with a schedule. The priority of change request should be high, medium or low.

According to GL3 in Fig. 9, the followings are the KPIs for Incident Management:

- number of failed changes implemented,

- number of emergency changes implemented,

- number of occurrences of process being circumvented,

- percentages of these numbers, and

- critical level of percentage to be defined and it should be escalated once the level is reached

\section{ITIL FRAMEWORK TESTING}

SMISS is a nursing information system developed with the Microsoft Visual Studio development tools. It runs under the Windows operating system; and the workstations are distributed in a local area network. In July 2010, a group of SMISS users and IT representatives were invited to discuss the implementation of ITIL practice as a case study for improving the service. At least one user from each clinic was invited to participate in this discussion.

Microsoft provides package guidance called Microsoft Operation Framework (MOF) that enables organizations to achieve mission-critical system reliability, availability, supportability, and manageability of IT solutions that are built with Microsoft technologies. To achieve the operations excellence, Microsoft combines the ITIL best practices in to MOF, and extends MOF to follow the ITIL code of practice. The MOF provides assessment templates with a set of questions with yes/no answers. Operation guidelines are provided to help users to answer these questions. The questionnaire concerning various performance criteria was prepared using the MOF assessment template. Because the questionnaire has been used before as a successful tool to measure the level of effectiveness of the IT services in an 
organization according to the MOF guidelines, the answers that were collected from the selected group of users can represent as an important test tool for the system.

All ITIL functions and processes are tested except Financial Management because the simplified data communication and Sharing (SDCS) adopts the financial processes according to the Government practice. At the same period of this research, there was a security audit process conducted by a third party vendor, as well. Most of the users in the test group were also participated in the security audit process to measure the level of effectiveness of Security Management.

In November 2010, the same group of SMISS users and IT representatives were invited to participate in the research to collect the posttest data. The answers to pretest and posttest data using the same questionnaire are presented in tables 1 and 2 below, respectively. The questionnaire was formatted in such a way that the ITIL functions and processes The count of positive feedback is presented in the following frequency distribution table, with statistics such as mean and variance.

TABLE I: FREQUENCY DISTRIBUTION OF SERVICE DESK RESULT

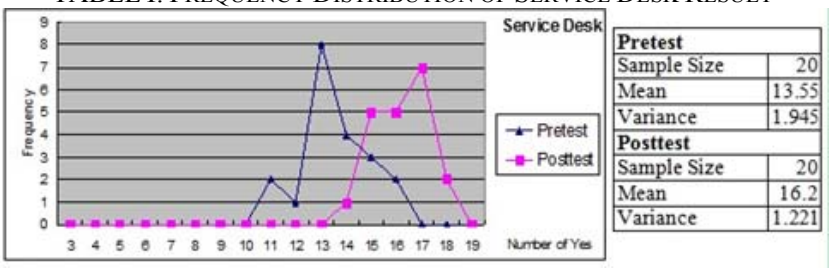

TABLE II: FREQUENCY DISTRIBUTION OF INCIDENT MANAGEMENT

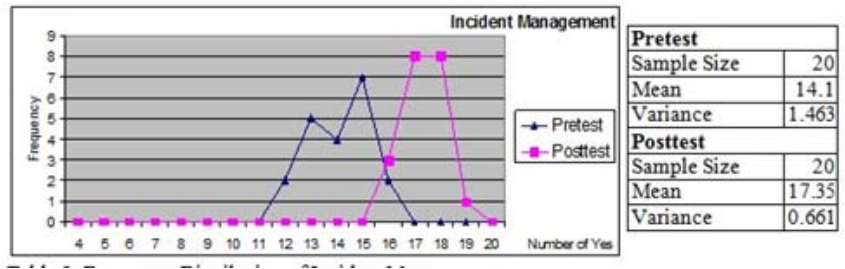

TABLE III: FREQUENCY DISTRIBUTION OF PROBLEM MANAGEMENT

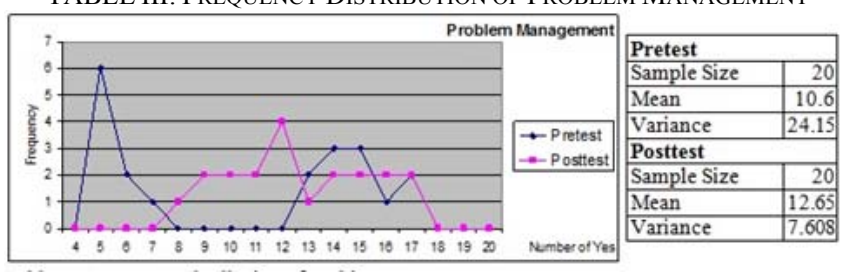

TABLE IV: FREQUENCY DISTRIBUTION OF CHANGE MANAGEMENT

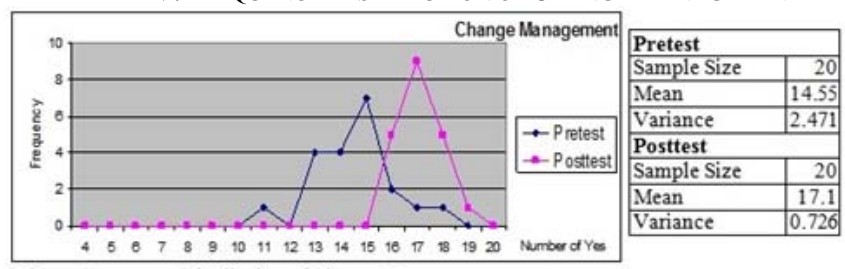

The mean values of pretest and posttest results are compared to check if there is an improvement in the positive feedback to the concerned support service. The mean values were tested using the t-Student test, and the t-values were calculated by using the formula below [19]:

$\mathrm{t}$-value $=($ Mean of posttest - Mean of pretest $) /$

square root (Variance of posttest / Sample size of posttest + Variance of pretest / Sample size of pretest)

Alpha level $=0.05$ of one tail test
Degree of freedom $=$ sample size of pretest + sample size of posttest $-2=38$

According t-distribution significance table, the critical value is 1.684 for one tail test.

Null Hypothesis - there is no difference between pre-test and post-test sample means for each of ITIL functions.

TABLE V: Null Hypothesis OF THE SERVICE

\begin{tabular}{|c|c|c|c|c|c|c|c|c|}
\hline & \multicolumn{3}{|c|}{ Pre-test } & \multicolumn{3}{|c|}{ Post-test } & \multirow[b]{2}{*}{ t-value } & \multirow{2}{*}{$\begin{array}{c}\text { Null } \\
\text { Hypothesis }\end{array}$} \\
\hline & $\%$ of Yes & Mean & Variance & $\%$ of Yes & Mean & Variance & & \\
\hline SD & $75 \%$ & 13.55 & 1.9447 & $90 \%$ & 16.2 & 1.2211 & 6.661 & Reject \\
\hline IM & $74 \%$ & 14.1 & 1.4632 & $91 \%$ & 17.35 & 0.6605 & 9.974 & Reject \\
\hline PM & $56 \%$ & 10.6 & 24.147 & $67 \%$ & 12.65 & 7.6079 & 1.627 & Accept \\
\hline ChM & $77 \%$ & 14.55 & 2.4711 & $90 \%$ & 17.1 & 0.7263 & 6.378 & Reject \\
\hline
\end{tabular}

Legend:

SD - Service Desk, I IM - Incident Management, PM - Problem Management, ChM - Chang Management, $\%$ of Yes - percentage of positive answer for the group

From the above table, the null hypothesis of no difference between pretest and posttest mean value of PM is accepted, which implies that there is no change in the positive feedback from the test group after the ITIL practices are implemented. The null hypothesis of the other ITIL processes is rejected since the mean values of posttest are larger than the mean values of pretest. It can be concluded that the test group shows more positive feedback after the ITIL practices are implemented.

The t-value analysis concludes whether the improvement is significant or not. The processes can be grouped as follows:

Significantly improved - SD, IM, and ChM.

Not improved - PM.

The t-test demonstrates whether the effect of the implementation of the ITIL practice guidelines into the service process improved the satisfaction of the test group, or not. To determine which process has to be further improved, the percentage of positive feedback is used. By setting targets of $80 \%$, PM has to be further improved.

\section{Conclusions}

Although the results of almost all KPIs have demonstrated some improvement, it did not fully meet initial expectations, as some processes didn't result a significant improvement. There are two major possible explanations for this outcome. Firstly, the duration of the test is not long enough for the test group to experience ample improvement. Some of the intended reengineering efforts weren't fully implemented during the period of this case study, as it required more time, effort, and budget. For example, the Problem Management required a focus group and a pool of technical expertise that was not possible during the pilot project. However, a case study like this one serves as a trigger for major reengineering of processes. It could motivate the senior management to allocate enough budgets and plan a gradual implementation of process reengineering. The ITIL framework consists of a well evaluated, explored and maintained set of guidelines. It certainly serves a tool for exploring process reengineering and improvements while meeting the budget constraints. The 
case study required a lot of coordination and consensus while identifying process improvements, establishing a process reengineering methodology, and constructing questionnaires for process evaluation. The experience gained in a case study like this one can alleviate the possibility of expensive mistakes if a major process reengineering is initiated at once. Actually, the customer company appreciated the efforts in this case study, and motivated for reengineering of companywide processes.

Further work to this research can focus on designing and creating various really simple syndication (RSS) feeds for data collection towards business process data analyzers that could identify the need for IT service support process reengineering, and a data decision support system (DSS) for real time intelligent business decisions.

\section{REFERENCES}

[1] A. Caster-Steel and W. Tan, "Implementation of IT Infrastructure Library (ITIL) in Australia: Progress and Success factors," 2005 IT Governance International Conference, Auckland, 14-15 Nov 2005.

[2] CCTA 2011, Information Technology Infrastructure Library, Central Computer and Telecommunications Agency, London, UK.

[3] M. Brenner, I. Radistic, and M. Schollmeyer, A Case-Driven Methodology for Applying the MNM service Model, in Proc. 8th International IFIP/IEEE Network Ops and Management Symposium, 2002.

[4] M. Brenner, "Classifying ITIL Processes; A Taxonomy under Tool Support Aspects," IEEE/IFIP International workshop on Business-Driven IT Management, pp. 19-28, 2006.

[5] C. Despont-Gros, H. Mueller, and C. Lovis, "Evaluating user interactions with clinical information systems: A model based on human-computer interaction models," Journal of Biomedical Informatics, vol. 38, pp. 244-255, 2005.

[6] D. Grigori, C. Fabio, C. Malu et al., "Business Process Intelligence," Computers In Industry, vol. 53, pp. 321-343, 2004.

[7] H. Xin, "IT Service support process meta-modeling based on ITIL," in Proc. International Conference on Data Storage and Data Engineering (DSDE), pp. 127-131, 2010.

[8] M. Jantti., "Improving Incident Management Processes in Two IT Service Provider companies," $22^{\text {nd }}$ International Workshop on Database and Expert Systems Applications (DEXA), pp. 26-30, 2011.

[9] A. Lahtela, M. Jantti, and J. Kaukola, "Implementing an ITIL-based IT Service Management Measurement System," in Proc International Conference on Digital Society (ICDS), pp. 249-254, 2010.

[10] T. Lucio-Nieto and R. Colomo-Palacios, "ITIL and the creation of a Service Management Office (SMO): A new challenge for IT professionals: An exploratory study of Latin American companies," $7^{\text {th }}$ Iberian Conference on Information Systems and Technologies (CISTI), 2012.

[11] S. Mingay and Govekar, "ITIL's Service-Level Management Strength is in Integration," Tactical Guidelines, Research Note, $25^{\text {th }}$ January 2002.

[12] L. W. Neuman, Social Research Methods: Qualitative and Quantitative Approaches, $3^{\text {rd }}$ edition, Boston: Allyn and Bacon, 1997.

[13] R. Pereira, and M. Mira da Silva, "A maturity model for implementing ITIL V3 in practice," in Proc $15^{\text {th }}$ IEEE International Enterprise
Distributed Object Computing Conference Workshops (EDOCW), 2011, pp. 259-268.

[14] B. Sommer and R. Sommer, A practical guide to behavioral research: Tools and techniques, $4^{\text {th }}$ ed., Oxford University Press, 1997.

[15] M. Spremic, Z. Zmirak, and K. Kraljevic, "IT and Business process performance management: Case study of ITIL implementation in Finance Service Industry," in Proc $30^{\text {th }}$ International conference on Information Technology Interfaces (ITI), 2008, pp. 243-250.

[16] W. M. P. van der Aalst and A. J. M. M. Weijters, "Process mining: a research agenda," Computers In Industry, vol. 53 pp. 231-244, 2004.

[17] W. M. P. van der Aalst, "Business Process Simulation for Operational Decision Support," BPM 2007 workshops, 2008

[18] R. K. Yin, "Case study research-design and methods," Applied social research methods series, vol. 5, Newbury Park: Sage, 1994.

[19] W. G. Zikmund, Business Research Methods, 6th edition, The Dryden Press, Forth Worth, 2000.

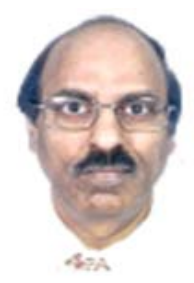

Malleswara Talla is a Professor (sessional) in the department of Decision Sciences \& MIS at John Molson School of Business (JMSB), Concordia University, Montreal. He received a B.Tech. degree from J.T.U. College of Engineering, Kakinada, India in 1979, a M.Tech. degree in 1981 from I.I.T., Kharagpur, India, and a Ph.D. degree from Concordia University, Montreal in 1995 specializing Computer Communications and Networks. He worked for Tata Consultancy Service (TCS), Bombay, and Societe Internationale de Telecommunications Aeronautique (S.I.T.A), Equant Canada Inc., and Orange Business Services for many years. Dr. Talla managed several projects in data communications, computer networks, and business performance excellence. Dr. Talla is a member of Canadian Operations Research Society (CORS), Professional Engineers of Ontario (PEO), Institute of Electrical and Electronics Engineers (IEEE), Project Management Institute (PMI), Association for Operations Management (APICS), and The Institute for Internal Controls (THEIIC). His teaching and research interests are mainly in Operations Management, Supply Chain Management, Information Systems, Process Re-engineering, Business Intelligence, Data Communications, Computer Networks, S/w Architecture, Design, and Development. Dr. Talla is a registered professional engineer in Canada.

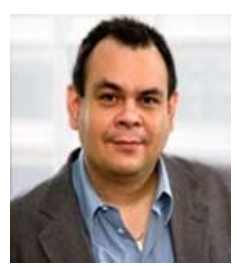

Raul Valverde is working as a Professor in the department of Decision Sciences \& MIS at John Molson School of Business (JMSB), Concordia University in Montreal. He holds a Bachelor of Science degree in Mathematics and Management from Excelsior College (US), a M. Eng. degree in Electrical \& Computer Engineering from Concordia University, and a Ph.D. degree in Information Systems from University of Southern Queensland, Australia. He has more than 17 years of professional experience in IT/IS, mathematical modeling, and financial analysis. Dr. Valverde is a member of the Society of Management Accountants, Canadian Operational Research Society, Institute of Internal Controls, Forensic CPA society, Professional Engineers of Ontario and the Association for Operations Management. His main research interests include Supply Chain Systems, Risk Management, E-business, Information Security and Auditing, Accounting and Financial Information Systems, Fraud Detection and Reengineering. Dr. Valverde is a registered professional engineer and accountant in Canada. 